\title{
OPEN Copper nanoparticles on controlled pore glass (CPG) as highly efficient heterogeneous catalysts for "click reactions"
}

\begin{abstract}
Abdolrahim A. Rafi, Ismail Ibrahem ${ }^{\bowtie}$ \& Armando Córdova $\bowtie$
We herein report that supported copper nanoparticles (CuNPs) on commercially available controlled pore glass (CPG), which exhibit high mechanical, thermal and chemical stability as compared to other silica-based materials, serve as a useful heterogeneous catalyst system for 1,3-dipolar cycloadditions ("click" reactions) between terminal alkynes and organic azides under green chemistry conditions. The supported CuNPs-CPG catalyst exhibited a broad substrate scope and gave the corresponding triazole products in high yields. The CuNPs-CPG catalyst exhibit recyclability and could be reuced multiple times without contaminating the products with $\mathrm{Cu}$.
\end{abstract}

The click chemistry concept invented by Sharpless and co-workers, represent one of the most highly efficient and powerful tools in synthetic organic chemistry ${ }^{1}$. It has been proven to be highly efficient, reliable, wide in scope, high yielding, stereospecific and can proceed under green chemistry conditions. In this context, the copper-(I) salt-catalyzed Huisgen 1,3-dipolar cycloaddition reaction between organic azides and alkynes is a stand out reaction in click chemistry. It works under mild conditions, tolerates several functionalities, recation conditions and have been used for a large varaiety of applications ${ }^{2-6}$. For example, the $\mathrm{Cu}(\mathrm{I})$-catalyzed alkyne-azide click chemistry (CuAAC) reaction have produced 1,2,3-triazole derivatives are employed as antibacterial agents, inhibitors, visualization and labeling of cells as well as several other medicinal chemistry applications ${ }^{7-12}$. It is also an important transformation for functionalization of gel-like ${ }^{13}$ and solid polysaccharides ${ }^{14}$, as well as different materials ${ }^{15,16}$. Copper nanoparticles (CuNPs) have proven to be more efficient catalysts for the CuAAC reaction as compared to copper metal salts, reducing both the catalyst loading and the reaction time ${ }^{17-22}$. In addition, the presence of both $\mathrm{CuI} / \mathrm{CuII}$ particles on the surface omits the use of ascorbate salts, which is neseccesery to add as a reducing agent for converting the $\mathrm{Cu}(\mathrm{II})$ precatalyst to the catalytically active $\mathrm{Cu}(\mathrm{I})$ species as well as avoiding aerobic oxidation of the $\mathrm{Cu}$ (I) back to a $\mathrm{Cu}(\mathrm{II})$ species $^{2,22}$. In addition, the choice of a heterogeneous systems allows for avoidance of contaminating the products with $\mathrm{Cu}$.

Among the different supports that can be prepared with tunable morphology and specific surface functionalization, controlled pore glass (CPG), which belongs to the family of silica-based materials, remains a relatively underdeveloped support within the nanocatalysis field ${ }^{23-27}$. It has several advantages over supports, which have been used for immobilization of metal nanoparticles: cost-effective synthesis, being commercial available with different types of surface functionalities, efficient mass-transfer, high surface area, tunable morphology, producibility in many different shapes, high mechanical, thermal and chemical stability. They are also used in industry for large scale applications. The resulting catalysts are more stable can also exhibit different selectivity as compared to the same types of nanocatalysts supported on mesocellular foam ${ }^{23,25,28-31}$, rice husk derived biosilicates ${ }^{32}$ and nanocellulose foam ${ }^{33}$. Hence, there is a need for further developments of CPG as a support within the nanocatalyst research area. In this context, we have previously assembled heterogeneous palladium nanocatalysts (PdNP) $)^{23,25}$ and copper nanocatalysts $(\mathrm{CuNP})^{24}$ on controlled pore glass $(\mathrm{CPG})$, which demonstrated notable levels of performance in catalysis. For example, in our previous work on the development of a CuNP-CPG nanocatalyst we fabricated an efficient catalyst for the aerobic oxidation of alcohols to their corresponding carbonyl compounds ${ }^{24}$. In comparison to other supported CuNP nanocatalysts used for the CuAAC reaction, the use of CPG as the support would allow for all of the above mentioned advantages (e.g. commercial availability, , efficient mass-transfer, high surface area, tunable morphology, controlled pore size, producibility in many different shapes, high mechanical, thermal and chemical stability) as well as being a robust material 


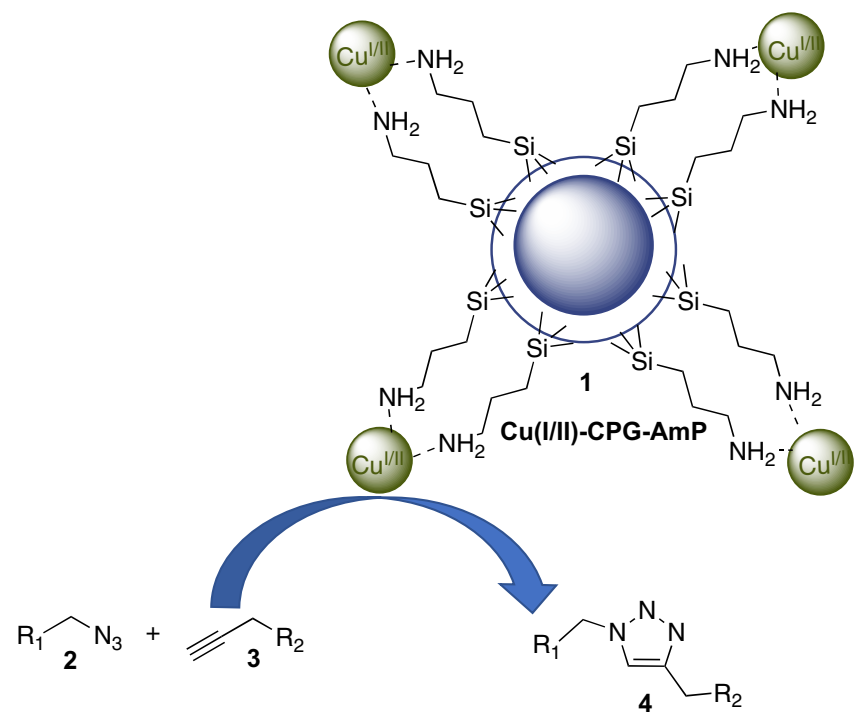

Figure 1. Cu-AmP-CPG (1)-catalyzed 1,3-dipolar cycloaddition between azides 2 and propargyl alcohols 3.

\begin{tabular}{|l|l|l|l|l|}
\hline Entry $^{\mathbf{a}}$ & Cu-Amp-CPG 1 (\%) & Temp. $\left({ }^{\circ} \mathbf{C}\right)$ & Time (h) & Conv. (\%) $^{\mathbf{b}}$ \\
\hline 1 & 5 & 70 & 0.3 & $>98$ \\
\hline 2 & 2 & 70 & 0.5 & $>98$ \\
\hline 3 & 1 & 70 & 0.7 & $>98$ \\
\hline 4 & 1 & r.t & 2 & 15 \\
\hline 5 & 1 & r.t & 18 & $>98$ \\
\hline 6 & 1 & 50 & 2 & 73 \\
\hline 7 & 1 & 50 & 2.4 & $>98$ \\
\hline 8 & - & 70 & 3 & - \\
\hline $9^{\mathrm{c}}$ & 1 & 70 & 0.8 & $>98$ \\
\hline $10^{\mathrm{c}}$ & 0.5 & 70 & 3 & $>98$ \\
\hline $11^{\mathrm{c}}$ & 0.25 & 70 & 4.7 & 98 \\
\hline $12^{\mathrm{d}}$ & 0.25 & 70 & 3 & 98 \\
\hline
\end{tabular}

Table 1. Initial examination and model reaction of catalytic 1,3-dipolar cycloaddition of benzyl azide 2a and propargyl alcohol $3 a$.<smiles>NCc1ccccc1</smiles>

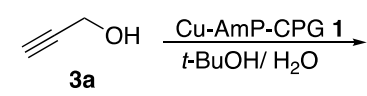

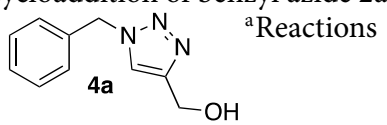

performed using nanocatalyst $\mathbf{1}, \mathbf{2 a}(0.1 \mathrm{mmol})$ and $\mathbf{3}(0.15 \mathrm{mmol})$ in $t-\mathrm{BuOH} / \mathrm{H}_{2} \mathrm{O} ; 1: 1(0.5 \mathrm{~mL})$. See SI for details. ${ }^{\mathrm{b}}$ Conversion determined by $\mathrm{H}^{1}$-NMR analysis using xylene as internal standard. ${ }^{\mathrm{c}} \mathbf{2 a}(0.1 \mathrm{mmol})$ and $\mathbf{3 a}$ $(0.1 \mathrm{mmol})$ in $t-\mathrm{BuOH} / \mathrm{H}_{2} \mathrm{O} ; 1: 1(0.5 \mathrm{~mL}) .{ }^{\mathrm{d}} \mathbf{2 a}(0.1 \mathrm{mmol})$ and $\mathbf{3 a}(0.1 \mathrm{mmol})$, neat reaction, no solvent.

approved for use in industrial synthesis and biochemistry applications. In fact, CPG is a preffered material in the synthesis and purification of oligonucleotides, RNA and DNA.

Based on our research interest in development of heterogeneous metal catalysts and the importance of the $\mathrm{CuAAC}$ transformation, we began to assemble and investigate a CuNP-CPG nanocatalyst $\mathbf{1}$ as a heterogeneous catalyst for the selective 1,3-dipolar cycloaddition between azides 2 and alkynes 3 for the synthesis of 1,4-triazoles 4 (Fig. 1).

Herein we disclose that $\mathrm{Cu}-\mathrm{AmP}-\mathrm{CPG}$ serves as a higly efficient and recyclable heterogeneous catalyst for the CuAAC ("click" chemistry) producing the corresponding 1,4-triazoles in high yields. The Cu-AmP-CPGcatalyzed click chemistry reactions proceed under environemtally friendly conditions and no $\mathrm{Cu}$ is leached during the process.

\section{Results and discussion}

We began fabricating our heterogeneous catalyst by assembling copper nanoparticles on aminopropyl-(AmP)functionalized CPG according to our previous procedures. The synthesized Cu-AmP-CPG (1) (5 mol\%) was next investigated as a heterogeneous catalyst for the 1,3-dipolar cycloaddition reaction between benzyl azide 2a and propargyl alcohol 3a in a $t-\mathrm{BuOH} / \mathrm{H}_{2} \mathrm{O}-1: 1$ mixture (Table 1, entry 1 ). After $1 \mathrm{~h}$, the initial experiment gave 
triazole $4 \mathrm{a}$ in $>98 \%$ conversion at $70{ }^{\circ} \mathrm{C}$. Encouraged by this result, we continued to probe the recation conditions. The key results are summarized in Table 1.

For example, it was also possible to run the cycloaddition with a significantly lower catalyst loading (1,2 mol $\%$ ), which gave nearly full conversion within $1 \mathrm{~h}$ (entry 2, Table 1). Further reduction of the catalyst loading increased the reaction time (entry 3 and 4, Table 1). Moreover, control experiments revealed that product 4a was not formed in the absence of nanocatalyst 1 (entry 8, Table 1). To our delight, changing the ratio between 2 and 3a to 1:1 instead of 1:1.5 gave nearly full conversion to 4 a using very low catalyst loadings (entries 10-12). In this context, the reaction without solvent (neat condition) was also effective at a low catalyst loading of $\mathbf{1}$ $(0.25 \mathrm{~mol} \%)$ (entry 12 , Table 1$)$. The copper nanocatalyst $\mathbf{1}$, were recycled from the neat reaction by washing with a fresh $t-\mathrm{BuOH} / \mathrm{H}_{2} \mathrm{O}(1: 1)$ mixture, which is a green solvent mixture. It is important that when the reaction proceed to completion, the desired product $4 \mathbf{a}$ is simply isolated by filtration of $\mathbf{1}$, washing $\left(t-\mathrm{BuOH} / \mathrm{H}_{2} \mathrm{O}(1: 1)\right)$ and final removal of the solvent. This avoids the use of silica-gel column chromatography techniques and toxic organic solvents. With these results in hand, we selected $t-\mathrm{BuOH} / \mathrm{H}_{2} \mathrm{O}(1: 1)$ as the solvent mixture for probing the reaction for different azides $\mathbf{2}$ and alkynes $\mathbf{3}$ over the neat reaction condition due to practical reasons regarding the recycling of the nanocatalyst $\mathbf{1}$ (Table 2). As depicted in Table 2, a variety of substrates were used to study the scope of the nanocatalyst 1-catalyzed "click" reaction between $\mathbf{2}$ and $\mathbf{3}$. The Cu-AmP-CPG 1-catalyzed 1,3-dipolar cycloaddition reactions were successful and afforded the corresponding triazoles (4a-4k) in high yields. Furthermore, we noticed that prolonged reaction times were required in some cases (entries 3 and 8).

Recyclability is an important and crucial factor in developing a heterogeneous catalyst. Thus, we performed recycling experiments of the Cu-AmP-CPG 1 catalyst (Figs. 2 and 3). We found that nanocatalyst 1 afforded product 4a in excellent conversion over eight consecutive reaction cycles. However, when examining the kinetics of the first three cycles of the Cu-AmP-CPG 1-catalyzed cycloadditions ${ }^{34,35}$, we found that the recation was completed much faster than the set time of $2 \mathrm{~h}$ and that the rate of reaction started to decrease after 2 cycles (Fig. 3). Thus, we had been using more catalyst than needed to achieve full conversion in the allotted time of Table 1 . We were also able to recycle catalyst 1 when using differen substrates (Table 3 ).

The leaching of $\mathrm{Cu}-\mathrm{AmP}-\mathrm{CPG}$ nanocatalyst 1 was also investigated. No leaching was observed. In fact, the elemental analysis of the resulting recation mixture after removal of catalyst $\mathbf{1}$ had less amount of copper than the reaction performed without catalyst 1 (Table 1, entry 8), which had a negligible amount of copper (i.e. less than $10 \mathrm{ppm}$ ). Thus, catalyst $\mathbf{1}$ does not leach. Elemental analysis of the product determined that no $\mathrm{Cu}$ was present. In addition, a hot filtration experiment was performed where catalyst $\mathbf{1}$ was removed when formation of $4 \mathrm{a}$ reached $10 \%$ by filtration. Next, the reaction mixtured was allowed to stir for 3 days without the presence of catalyst 1 . No formation of product 4 a was observed.

The $\mathrm{Cu}$ nanocatalyst was characterized by a number of analytic techniques, including transmission emission microscopy (TEM), scanning electron microscopy (SEM), X-ray photoelectron spectroscopy (XPS) and elemental analysis by inductively coupled plasma optical emission spectrometry (ICP-QES ${ }^{24}$. The TEM analysis, performed here revealed the Cu-Amp-CPG nanocatalyst (Fig. 4) displayed a well-dispersed and uniform pattern of nanoparticles in the size range $1-20 \mathrm{~nm}$, with an average particle size of $6.4 \mathrm{~nm}$. The total amount of Cu of AmP-CPG 1 was $3.3 \mathrm{wt} \%$ as determined by elemental analysis. The XPS analyses revealed that the manufactured $\mathrm{Cu}-\mathrm{AmP}-\mathrm{CPG}$ nanocatalyst 1 had a $\mathrm{Cu}(\mathrm{II}) / \mathrm{Cu}(\mathrm{I})$ atomic ratio of 3.2:1. We also performed XPS analysis on the recovered nanocatalyst $\mathbf{1}$ after completed reaction, which revealed only $\mathrm{Cu}(\mathrm{I})$ in the composition.

\section{Conclusions}

In summary, we have shown that $\mathrm{Cu}$ NPs can be successfully immobilized on controlled pore glass to form $\mathrm{Cu}-\mathrm{AmP}-\mathrm{CPG} 1$ and next used as a heterogeneous copper nanocatalyst for "click" chemistry without the use of ascorbate as a reducing agent. With just a small nanocatalyst loading (0.25-1 mol\%), 1-catalyzed a range of Huisgen 1,3-dipolar cycloadditions with high efficiency exhibiting a broad substrate scope to give the corresponding 1,4-triazole products in high yields. The $\mathrm{Cu}$-AmP-CPG catalyst was simply recycled and multiple reaction cycles. However, we found that the rate of reaction decreases after 2 cycles and this should be taken in account when investigating silica based Cu NPG catalysts ${ }^{20,21}$. The concept of immobilizing noble metals such as Cu on recyclable CPG allows for future development of sustainable and green chemical approaches that should find relevant and sutible future applications in additional chemical transfromations.

\section{Methods}

General procedure for the catalytic 1,3-dipolar cycloaddition between 2 and 3. A 6-mL microwave vial with a magnetic stir bar was charged with azide compound 2 (1.0 mmol, 1.0 equiv. $)$ and $\mathrm{Cu}(\mathrm{I} / \mathrm{II})-\mathrm{AmP}-$ CPG (5.0 mg, $0.25 \mathrm{~mol} \%)$. Next, alkyne 3 (1.0 mmol, 1.0 equiv.) and solvent $\left(t-\mathrm{BuOH}: \mathrm{H}_{2} \mathrm{O}, 1: 1,5 \mathrm{~mL}\right)$ were added to the vial and the resulting mixture was allowed to stir at $70^{\circ} \mathrm{C}$. After $3 \mathrm{~h}$ of stirring, the solids were separated by centrifugation and the supernatant was removed. Next, additional solvent $\left(t-\mathrm{BuOH}: \mathrm{H}_{2} \mathrm{O}, 1: 1,5 \mathrm{~mL}\right)$ was added and the solids were washed and separated by centrifugation again. After removal of the supernatant, the combined solvents were evaporating under reduced pressure to afford the corresponding pure triazole 4.

Procedure for recycling of the Cu-AmP-CPG nanocatalyst 1. A 6-mL microwave vial with a magnetic stir bar was charged with azide compound $2 \mathbf{a}(0.25 \mathrm{mmol}, 1.0$ equiv.) and Cu(I/II)-AmP-CPG (10 mg, $5 \mathrm{~mol} \%)$. Next, alkyne $3 \mathrm{a}(0.38 \mathrm{mmol}, 1.5$ equiv. $)$ and solvent $\left(t-\mathrm{BuOH}: \mathrm{H}_{2} \mathrm{O}, 1: 1,1.3 \mathrm{~mL}\right)$ were added to the vial and the resulting mixture was allowed to stir at $70^{\circ} \mathrm{C}$. After $2 \mathrm{~h}$ of stirring, the solids were separated by centrifugation and the supernatant was removed. Next, additional solvent $\left(t-\mathrm{BuOH}: \mathrm{H}_{2} \mathrm{O}, 1: 1,5 \mathrm{~mL}\right)$ was added and the solids were washed and separated by centrifugation again. After removal of the supernatant, the combined solvents were evaporating under reduced pressure to afford the corresponding pure triazole $\mathbf{4 a}$. The solid nano- 


\begin{tabular}{|c|c|c|c|c|c|c|}
\hline Entry & $\mathrm{R}$ & $\mathbf{R}^{1}$ & \begin{tabular}{|l|} 
Cat \\
(mol\%)
\end{tabular} & Prod & Time $(\mathbf{h})$ & Yield $[\%]^{\mathrm{a}}$ \\
\hline 1 & $\mathrm{Ph}$ & $\mathrm{CH}_{2} \mathrm{OH}$ & 0.25 & & 4.7 & 95 \\
\hline 2 & $\mathrm{Ph}$ & $n$-But & 0.25 & & 6 & 93 \\
\hline 3 & $\mathrm{Ph}$ & $\mathrm{Ph}$ & 1 & & 48 & 85 \\
\hline 4 & $\mathrm{Ph}$ & $\mathrm{CH}_{2} \mathrm{CH}\left(\mathrm{CO}_{2} \mathrm{Me}\right)_{2}$ & 0.5 & & 3 & 92 \\
\hline 5 & $\mathrm{Ph}$ & & 0.5 & & 7 & 95 \\
\hline 6 & $\mathrm{Ph}$ & & 0.5 & & 3 & 87 \\
\hline 7 & $\mathrm{Ph}$ & & 0.25 & & 5 & 92 \\
\hline 8 & $\mathrm{Ph}$ & & 1 & & 9 & 93 \\
\hline 9 & $n-\mathrm{C}_{15} \mathrm{H}_{31}$ & $\mathrm{CH}_{2} \mathrm{OH}$ & 0.25 & & 6 & $90(81)^{\mathrm{b}}$ \\
\hline 10 & $n-\mathrm{C}_{15} \mathrm{H}_{31}$ & $n-\mathrm{C}_{4} \mathrm{H}_{9}$ & 0.5 & & 7 & 81 \\
\hline 11 & $n-\mathrm{C}_{15} \mathrm{H}_{31}$ & AcO & 0.25 & & 4 & 94 \\
\hline \multicolumn{7}{|c|}{ Continued } \\
\hline
\end{tabular}




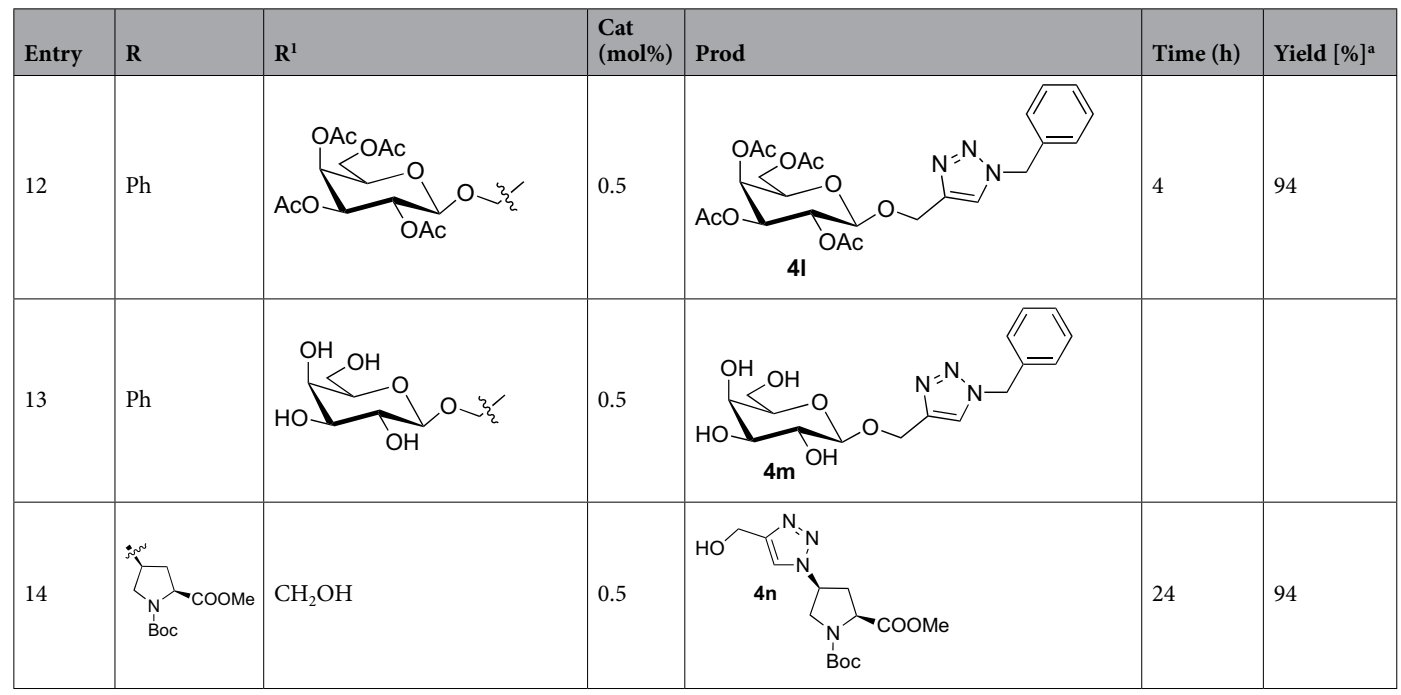

Table 2. Scope of the 1,3-dipolar cycloaddition reaction catalyzed by $\mathrm{Cu}$-AmP-CPG 1.

$\mathrm{R}_{2} \mathrm{~N}_{3}+\mathrm{R}^{1} \frac{\mathrm{Cu}-\mathrm{AmP}-\mathrm{CPG} 1(0.25-1 \mathrm{~mol} \%)}{\mathrm{t}-\mathrm{BuOH} / \mathrm{H} 2 \mathrm{O}(1: 1), 70^{\circ} \mathrm{C}}$

(0.25 mol\%), $2(0.4 \mathrm{mmol})$ and $3(0.4 \mathrm{mmol})$ in $t-\mathrm{BuOH} / \mathrm{H}_{2} \mathrm{O} ; 1: 1(2 \mathrm{~mL})$ at $70{ }^{\circ} \mathrm{C}$ for the time shown. See SI for details. ${ }^{a}$ Isolated yield. ${ }^{b}$ Neat condition (no solvent), 1 (1 mol\%), $2 \mathrm{~h}$.

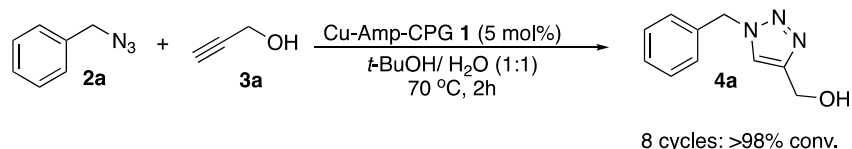

No. of cycles

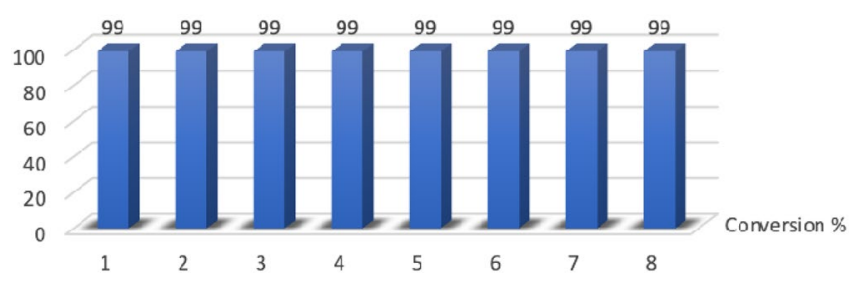

Figure 2. Recycling experiments of Cu-AmP-CPG 1-catalyzed 1,3-dipolar cycloaddition between benzyl azide 2a and propargyl alcohol 3a. Conversion to $4 \mathbf{a}$.

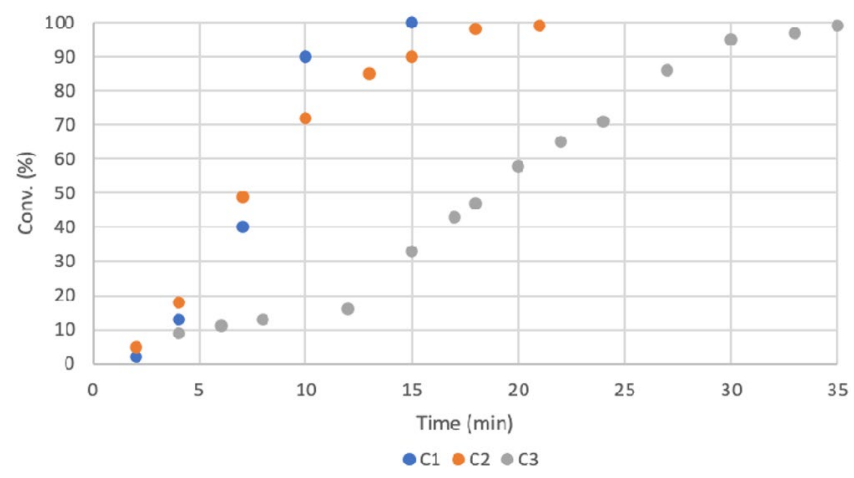

Figure 3. Formation of $\mathbf{4 a}$ for cycles $\mathrm{C} 1$ to $\mathrm{C} 3$ for the Cu-AmP-CPG 1-catalyzed 1,3-dipolar cycloaddition between benzyl azide $2 \mathbf{a}$ and propargyl alcohol 3a. $\mathrm{C} 1=$ cycle $1, \mathrm{C} 2=$ cycle 2 and $\mathrm{C} 3=$ cycle 3 . 


\begin{tabular}{|c|c|c|c|c|}
\hline Cycle & $R^{1}$ & Product & Time (min) & Conv. (\%) \\
\hline 1 & $\mathrm{CH}_{2} \mathrm{OH}$ & & 15 & $>99$ \\
\hline 2 & $n-\mathrm{C}_{4} \mathrm{H}_{9}$ & & 40 & $>99$ \\
\hline 3 & $O-p-\mathrm{MeO}-\mathrm{C}_{6} \mathrm{H}_{4}$ & & 40 & $>99$ \\
\hline
\end{tabular}

Table 3. Recycling with different alkynes. Reactions performed using catalyst $1(5 \mathrm{~mol} \%), 2(0.1 \mathrm{mmol})$ and $3(0.15 \mathrm{mmol})$ in $t$ - $\mathrm{BuOH} / \mathrm{H}_{2} \mathrm{O} ; 1: 1(0.5 \mathrm{~mL})$ at $70{ }^{\circ} \mathrm{C}$.
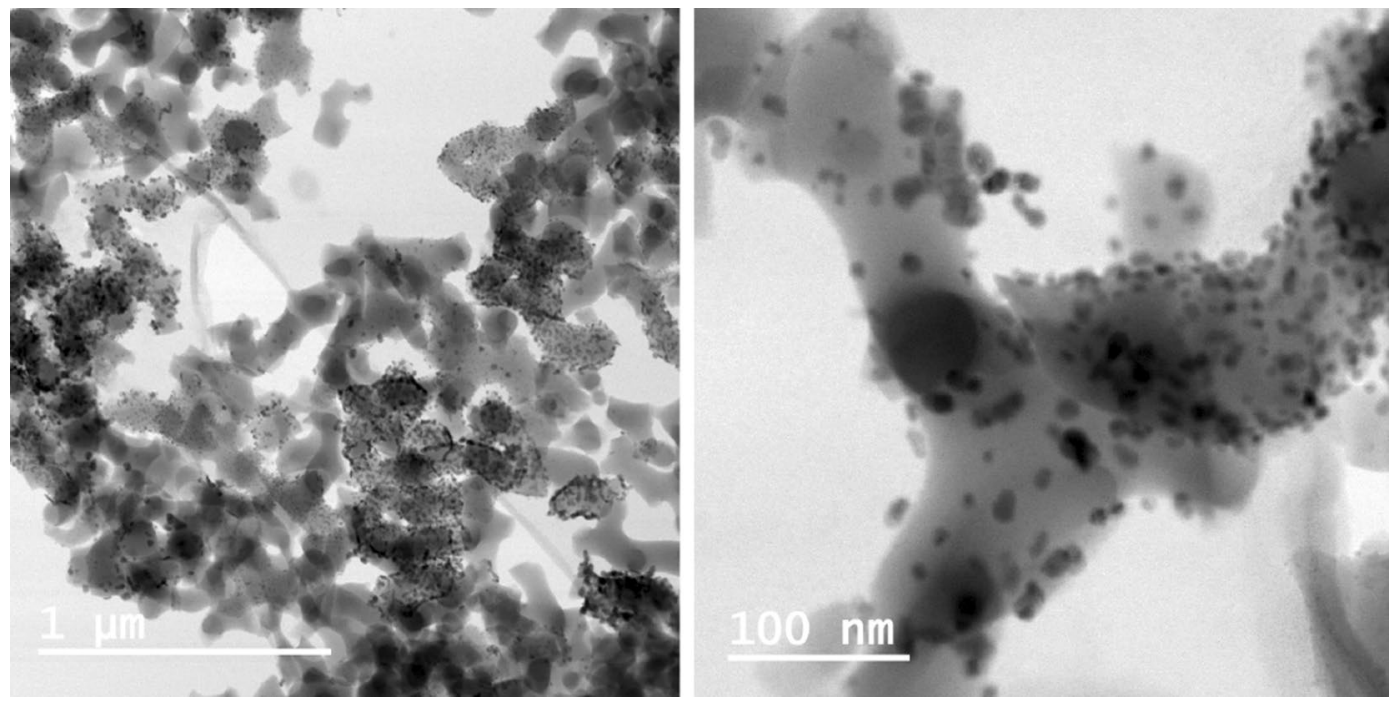

Figure 4. Transmission electron micrographs (TEM) of the mixed valence Cu-AmP-CPG nanocatalyst 1.

catalyst 1 that was separated from the reaction mixture by centrifugation was washed once with the reaction solvent $t-\mathrm{BuOH} / \mathrm{H}_{2} \mathrm{O}(1: 1)$ and next re-utilized in the next experimental cycle as described above.

Procedure for the synthesis of Cu-AmP-CPG (1). To a suspension of amine functionalized CPG (1.0 g, 1 equiv. amine content) in deionized water $(25 \mathrm{~mL}, \mathrm{pH} 9)$, was added a suspension of copper(II) trifluoromethanesulfonate $\left(\mathrm{Cu}(\mathrm{OTf})_{2}, 0.3 \mathrm{~g}\right.$, 2 equiv.) in deionized water $(20 \mathrm{~mL}, \mathrm{pH} 9)$ at room temperature. After stirring for $24 \mathrm{~h}$, the prepared $\mathrm{Cu}(\mathrm{II})-\mathrm{AmP}-\mathrm{CPG}$ was transferred to a centrifuge vial $(50 \mathrm{~mL})$ and was washed with deionized $\mathrm{H}_{2} \mathrm{O}(3 \times 35 \mathrm{~mL})$ and acetone $(3 \times 35 \mathrm{~mL})$ by centrifugation. The washed $\mathrm{Cu}(\mathrm{II})$-AmP-CPG was collected by decantation and dried overnight under reduced pressure. Next, the dry $\mathrm{Cu}$ (II)-AmP-CPG was suspended in deionized water $(35 \mathrm{~mL})$ and $\mathrm{NaBH}_{4}(20$ equiv. $)$ in deionized water $(15 \mathrm{~mL})$ was added slowly at room temperature. After stirring for $45 \mathrm{~min}$, the resulting $\mathrm{Cu}(\mathrm{I} / \mathrm{II})-\mathrm{AmP}-\mathrm{CPG}$ nanocatalyst was transferred to a centrifuge vial $(50 \mathrm{~mL})$ and was washed with deionized $\mathrm{H}_{2} \mathrm{O}(3 \times 35 \mathrm{~mL})$ and acetone $(3 \times 35 \mathrm{~mL})$ by centrifugation and subsequent removal of the supernatant. The washed $\mathrm{Cu}(\mathrm{I} / \mathrm{II})-\mathrm{AmP}-\mathrm{CPG}$ was finally dried for $48 \mathrm{~h}$ under reduced pressure. 
Received: 15 May 2020; Accepted: 13 November 2020

Published online: 25 November 2020

\section{References}

1. Rostovtsev, V. V., Green, L. G., Fokin, V. V. \& Shaprless, K. B. A stepwise Huisgen cycloaddition process: copper(I)-catalyzed regioselective "Ligation" of azides and terminal alkynes. Angew. Chem. Int. Ed. 41, 2596-2599 (2002).

2. Himo, F. et al. Copper(I)-catalyzed synthesis of azoles. DFT study predicts unprecedented reactivity and intermediates. Am. Chem. Soc. 127, 210-216 (2005).

3. Lee, L. V. et al. A potent and highly selective inhibitor of human a-1,3-Fucosyltransferase via click chemistry. J. Am. Chem. Soc. 125, 9588-9589 (2003).

4. Manetsch, R. et al. In situ click chemistry: enzyme inhibitors made to their own specifications. J. Am. Chem. Soc. 126, 12809-12818 (2004).

5. Tornøe, C. W. \& Meldal, M. American Peptide Society and Kluwer 263-264 (Academic Publications, San Diego, 2001).

6. Tornøe, C. W., Christensen, C. \& Meldal, M. Peptidotriazoles on solid phase: [1,2,3]-Triazoles by regiospecific copper(I)-catalyzed 1,3-dipolar cycloadditions of terminal alkynes to azides. J. Org. Chem. 67, 3057-3064 (2002).

7. Smit, F. J. et al. Synthesis and antimycobacterial activiy of disubstituted benzyltriazoles. Med. Chem. Res. 28, 2279-2293 (2019).

8. Labadie, G. R., De la Iglesia, A. \& Morbidoni, H. R. Targeting tuberculosis through a smaii focused library of 1,2,3-triazoles. Mol Divers 15, 1017-1024 (2011).

9. Doiron, J. et al. Synthesis and structure-activity relationship of 1-and 2-substituted-1,2,3-triazole letrozole-based analogues as aromatase inhibitors. Eur. J. Med. Chem. 46, 4010-4024 (2011).

10. Kolb, H. C. \& Sharbless, K. B. The growing impact of click chemistry on drug discovery. Drug Disc. Today 8, 1128-1137 (2003).

11. Tron, G. C. et al. Click chemistry reactions in medicinal chemistry: applications of the 1,3-dipolar cycloaddition between azides and alkynes. Med. Res. Rev. 28, 278-308 (2008).

12. Moorhouse, A. D. \& Moses, J. E. Click chemistry and medicinal chemistry: a case of "cyclo-addiction". ChemMedChem 3, 715-723 (2008).

13. Punna, S., Kaltgrad, E. \& Finn, M. G. "Clickable" agarose for affinity chromatography. Biocojugate Chem. 16, 1536-1541 (2005).

14. Hafren, J., Zou, W. \& Córdova, A. Heterogeneous "organoclick" derivatization of polysaccharides. Macromol. Rapid. Commun. 27, $1362-1366$ (2006).

15. Nandiva, H., Jiang, X. \& Lahann, J. Click Chemistry: versatility and control in the hands of materials scientists. Adv. Mater. 19, 2197-2208 (2007)

16. Lutz, J.-F. 1,3-Dipolar cycloadditions of azides and alkynes: a universal ligation tool in polymer and materials science. Angew. Chem. Int. Ed. 46, 1018-1025 (2007).

17. Kidwai, M., Mishra, N. K., Bansal, V., Kumar, A. \& Mozumdar, S. Novel one-pot Cu-nanoparticles-catalyzed Mannich reaction. Tetrahedron Lett. 50, 1355-1358 (2009).

18. Phithak, D., Sremethean, S., Arjsalee, J. \& Saejueng, P. Nanocopper-catalyzed cross-coupling reaction for the synthesis of diarylethers. APCBEE Procedia 3, 161-166 (2012)

19. Park, I. S., Kwon, M. S., Kim, Y., Lee, J. S. \& Park, J. Heterogeneous copper catalyst for the cycloaddition of azides and alkynes without additives under ambient conditions. Org. Lett. 10, 497-500 (2008).

20. Gwande, M. B. et al. $\mathrm{Cu}$ and $\mathrm{Cu}$-based nanoparticles: synthesis and applications in catalysis. Chem. Rev. 116, 3722-3811 (2016).

21. Alonso, F., Moglie, Y. \& Radivoy, G. Copper nanoparticles in click chemistry. Acc. Chem. Res. 48, 2516-2528 (2015).

22. Sanchez-Sanchez, A., Pérez-Baena, I. \& Pomposo, J. A. Advances in click chemistry for single-chain nanoparticle construction. Molecules 18, 3339-3355 (2013).

23. Deiana, L. et al. Efficient and highly enantioselective aerobic oxidation-michael-carbocyclization cascade transformations by integrated Pd(0)-CPG nanoparticle/chirale amine relay catalysis. Synthesis 46, 1303-1310 (2014).

24. Ibrahem, I. et al. Copper nanoparticles on controlled pore glass and TEMPO for the aerobic oxidation of alcohols. Chem. Nano. Mat. 4, 71-75 (2018).

25. Palo-Nieto, C. et al. Integrated heterogeneous metal/enzymatic multiple relay catalysis for eco-friendly and asymmetric synthesis. ACS Catal. 6, 3932-3940 (2016).

26. Shen, C., Wang, Y. J., Xu, J. H., Wang, K. \& Luo, G. S. Size control and catalytic activity of highly dispersed Pd nanoparticles supported on porous glass beads. Langmuir 28, 7519-7527 (2012).

27. Li, J., Mau, A.W.-H. \& Strauss, C. R. The use of palladium on porous glass for catalytic coupling reactions. Chem. Commun. 14, $1275-1276$ (1997).

28. Shakeri, M., Tai, C.-W., Göthelid, E., Oscarsson, S. \& Bäckvall, J.-E. Small Pd nanoparticles in large pores of mesocellular foam: an excellent catalyst for racemization of amines. Chem. Eur. J. 17, 13269-13273 (2011).

29. Deiana, L. et al. Highly enantioselective cascade transformations by merging heterogeneous transition metal catalysis with asymmetric aminocatalysis. Sci. Rep 2, 851 (2012).

30. Afewerki, S., Palo-Nieto, C. \& Córdova, A. Efficient heterogeneous palladium-catalyzed transfer hydrogenolysis of benzylic alcohols by formic acid. Synthesis 52, 2330-23336 (2020).

31. Deiana, L. et al. Combined heterogeneous metal/chiral amine: multiple relay catalysis for versatile eco-friendly synthesis. Angew. Chem. Int. Ed. Engl. 53, 3447-34451 (2014).

32. Afewerki, S., Franco, A., Balu, A. M., Luque, R. \& Córdova, A. Sustainable and recyclable heterogenous palladium catalysts from rice husk-derived biosilicates for Suzuki-Miyaura cross-couplings, aerobic oxidations and stereoselective cascade carbocyclizations. Sci. Rep. 10, 6407 (2020).

33. Li, M.-B. et al. Silver-triggered activity of a heterogeneous palladium catalyst in oxidative carbonyl reactions. Angew. Chem. Int. Ed. 59, 1039 (2020).

34. Scott, S. L. A metter of life(time) and death. ACS Catal. 8, 8597-8599 (2018).

\section{Acknowledgements}

Financial support by Mid Sweden University and the European Union is acknowledget.

\section{Author contributions}

A.C. and I.I. designed and planed the research, A.A.R. and I.I. performed the experiments. A.C. and I.I. wrote the paper. All the authors analyzed the data.

\section{Funding}

Open Access funding provided by Mid Sweden University. 


\section{Competing interests}

The authors declare no competing interests.

\section{Additional information}

Supplementary information is available for this paper at https://doi.org/10.1038/s41598-020-77629-3.

Correspondence and requests for materials should be addressed to I.I. or A.C.

Reprints and permissions information is available at www.nature.com/reprints.

Publisher's note Springer Nature remains neutral with regard to jurisdictional claims in published maps and institutional affiliations.

(c) (i) Open Access This article is licensed under a Creative Commons Attribution 4.0 International cc) License, which permits use, sharing, adaptation, distribution and reproduction in any medium or format, as long as you give appropriate credit to the original author(s) and the source, provide a link to the Creative Commons licence, and indicate if changes were made. The images or other third party material in this article are included in the article's Creative Commons licence, unless indicated otherwise in a credit line to the material. If material is not included in the article's Creative Commons licence and your intended use is not permitted by statutory regulation or exceeds the permitted use, you will need to obtain permission directly from the copyright holder. To view a copy of this licence, visit http://creativecommons.org/licenses/by/4.0/.

(c) The Author(s) 2020 